\title{
The Hysteretic Behavior of Single C-type Cold-formed Cantilevered Member
}

\author{
Xiu-Li WANG ${ }^{1, b}$, Yun-Peng CHU ${ }^{1, a,{ }^{*}, \text { Rong WANG }}{ }^{2, c}$ \\ ${ }^{1}$ Lanzhou University of Technology, Lanzhou 730050, china \\ ${ }^{2}$ Southwest University of Science and Technology, Mianyang 621010, China \\ a377309083@qq.com, b1135739056@qq.com, c1054842344@qq.com \\ *Corresponding author
}

Keywords: Cold-formed Thin-walled Steel, Material Test, FEM, Hysteretic Behavior.

\begin{abstract}
The flange and web of cold-formed thin-walled steel have small thickness and big width-thickness ratios, its mechanical properties are very different from ordinary steel members. In this paper, we performed three groups of the finite element hysteretic performance analysis of cantilevered member based on the cold-formed thin-walled steel resistance test, the results show: component get bending torsion coupling damage under cyclic loads; Sectional dimensions of members under cyclic loading has a greater impact on the carrying capacity; The batch cold-formed thin-walled steel with good material ductility.
\end{abstract}

\section{Introduction}

The gradual implementation of the building industrialization policy making steel building housing the rapid development, cold-formed thin-walled steel structures concern owners and researchers due to fast construction speed, high degree of assembly, give full play to the advantages of the mechanical properties of steel.

Cold-formed thin-walled steel residential system mainly consists of wall, floor, roof and maintenance of structures. Wall structure consists of dense keel, consisting of upper and lower rails and wall panels; Floor structure consists of floor beams, floor panels and ceiling; Roof structure consists of roof trusses, roof, ceiling composition; Cold-formed thin-walled steel structural system is a plate ribs structural, the flat stiffness of plate rib structure is large, can resist horizontal wind and seismic loads. 1947, Green, Winter and Cuykendall [2] conducted theoretical analysis and experimental research on the interaction between wall panels and wall stud cold-formed thin-walled steel composite wall, study results suggest that in the combination wall, Wall panels connected to the column mainly from the lateral elastic support role. 1993-1994, Miller TH and Pekoz T. [3] conducted a combination of vertical bearing capacity of a full scale wall test, the trial studied force performance of channel, double-sided flat and double-sided gypsum wallboard (GWB board) supports wall stud under axial loads and the changes in carrying capacity of wall stud when load eccentricity. The results show: In the composite wall, the pitch wall stud has a less impact on capacity; the supporting provided to wall stud of gypsum wallboard is different from the skin. Zuyan Shen conducted reliability analysis of a number of yield strength of 550MPa high-strength cold-formed thin-walled steel axis of compression members. Considered after reasonably determined by the thickness of the classification of high strength cold-formed thin-walled steel design specifications, analysis on ultimate bearing capacity of axial compression members can be carried out efficiently based on current "cold-formed steel Technical Specifications" (GB 50018-2002) [5] given the method considered panel stability calculation section effective width-thickness ratios, and to meet the requirements of a reliable indicator of a predetermined design. Chang'an University, Yu Shi [6] conducted test and finite element analysis for cold-formed thin-walled Lipped channels axial bearing capacity of components. The results showed that: ultimate bearing capacity of Cold-formed thin-walled C-shaped steel axial compression members with member increasing flange thickness ratio, web thickness ratio, slenderness ratio and the strength of steel decreases. And proposed strength reduction method used to calculate $\mathrm{C}$ steel axial 
compression component capacity, given axial compressive component capacity formula consider local buckling, overall buckling and distortion bucking caused yield strength reduction of components.

The flange and web of cold-formed thin-walled steel have small thickness and big width-thickness ratios, its mechanical properties are very different from ordinary steel members. A correct understanding of the performance of cold-formed thin-walled steel members is the foundation to study the overall structure. Therefore, this article conduct hysteretic performance analysis of a single $\mathrm{C}$-type cold-formed steel member with finite element based on the cold-formed thin-walled steel material mechanical performance tests.

\section{Material Test}

The material of specimen is Q235B grade galvanized steel, the nominal thickness of the substrate is $1.0 \mathrm{~mm}$. Production Sample according to the existing regulations metallic materials stretch test Part 1: Room temperature test method (GB / T228.1-2010) [7], figure 1 shows the sample size. In the figure, $b=15 \mathrm{~mm}, \mathrm{~s} 0=\mathrm{b} \times \mathrm{t}=15 \mathrm{~mm} 2, \mathrm{~L} 0=11.3=44 \mathrm{~mm}, \mathrm{Lc}=\mathrm{L} 0+20=64 \mathrm{~mm}$.

Material test equipment using computer control $100 \mathrm{kN}$ universal testing machine, using electronic extensometer for measuring strain, computer full automatic control of load and record test data, test equipment shown in Figure 2. Failure characteristics of the specimen shown in Figure 3 , the three groups of specimen are certain "necking" phenomenon before the destruction.

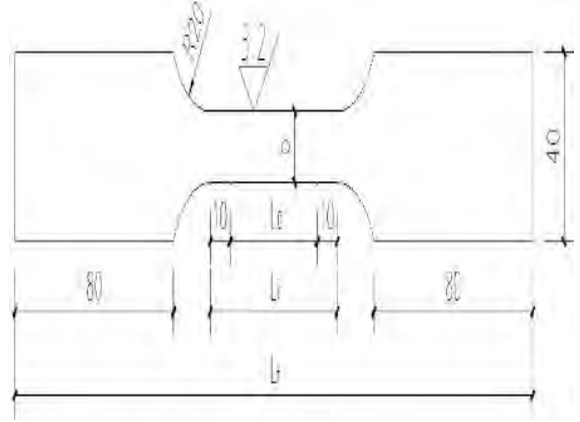

Fig. 1 Size of Material Properties Specimen

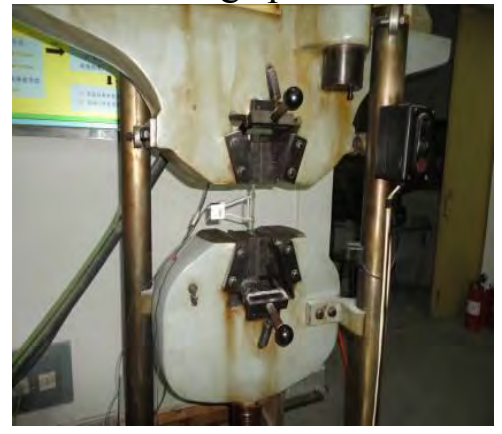

Fig. 2 Material Testing Machine

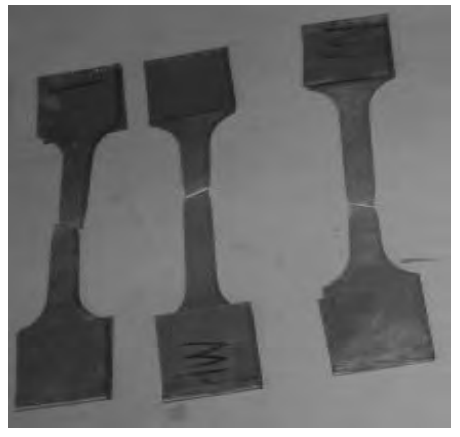

Fig. 3 Failure Modes of Specimen

The elastic modulus, yield strain, peak stress and ultimate strain of steel specimens in each group can be obtained by material test, determine the basic mechanical parameters of steel by averaging method, the main test results shown in Table 1.

Tab. 1 Main Material Test Results

\begin{tabular}{cccccccc}
\hline $\begin{array}{c}\text { Specimen } \\
\text { Number }\end{array}$ & Thickness(mm) & $\begin{array}{c}\text { Yield } \\
\text { Strength(Mpa) }\end{array}$ & $\begin{array}{c}\text { Elastic } \\
\text { modulus(Gpa) }\end{array}$ & $\begin{array}{c}\text { Yield } \\
\text { strain(\% } \\
\text { ) }\end{array}$ & $\begin{array}{c}\text { Peak } \\
\text { stress } \\
\text { (Mpa) }\end{array}$ & $\begin{array}{c}\text { Elongation( } \\
\%)\end{array}$ & $\begin{array}{c}\text { Sectional } \\
\text { shrinkage( } \\
\%)\end{array}$ \\
\hline MP1 & 0.90 & 312.59 & 163.06 & 0.19 & 385.19 & 22.47 & 33.33 \\
MP2 & 0.94 & 306.38 & 155.08 & 0.20 & 373.05 & 22.29 & 33.20 \\
MP3 & 0.92 & 314.49 & 162.41 & 0.19 & 378.99 & 22.56 & 35.33 \\
Mean & 0.92 & 311.16 & 160.19 & 0.19 & 379.07 & 22.44 & 33.95 \\
\hline
\end{tabular}

\section{Finite Element Hysteresis Test}

\section{Specimen Cross-sectional Dimension}

We conduct three C-type member's single cantilever hysteretic performance analysis involved in the follow-up node test, cross-section in the form of components and detailed parameters as shown in Figure 4 and Table 2. Section height is $1500 \mathrm{~mm}$. 


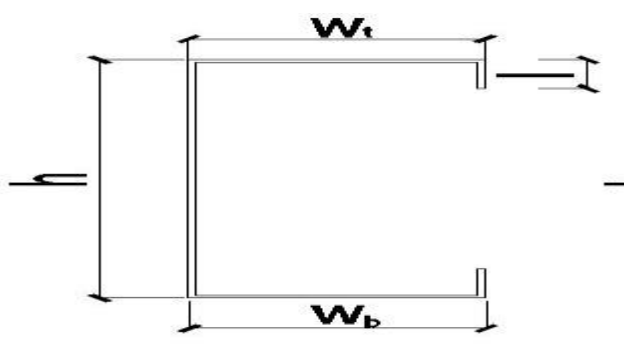

Fig. 4 The Section of C-type Steel

Tab. 2 the Sectional Dimensions of C-type Steel

\begin{tabular}{|c|c|c|c|c|c|}
\hline Type & $\mathrm{h}(\mathrm{mm})$ & $\mathrm{W}_{\mathrm{t}}(\mathrm{mm})$ & $\mathrm{w}_{\mathrm{b}}(\mathrm{mm})$ & $\mathrm{t}(\mathrm{mm})$ & $1(\mathrm{~mm})$ \\
\hline $\mathrm{C} 89$ & 89.0 & 44.5 & 44.5 & 1.00 & 12 \\
\hline C160 & 160 & 40 & 40 & 1.00 & 10 \\
\hline C205 & 205 & 40 & 40 & 1.00 & 10 \\
\hline
\end{tabular}

Note: $t$ represents the nominal thickness of specimen, the actual thickness of the specimen as same as the test, the actual thickness of $\mathrm{t}$ is $0.92 \mathrm{~mm}$.

\section{Material Constitutive}

Combine with material test( material yield phase is very short during the test), material constitutive will be reduced to three phase, that is elastic phase, strengthening phase and neck contraction phase, as shown in Figure 5.

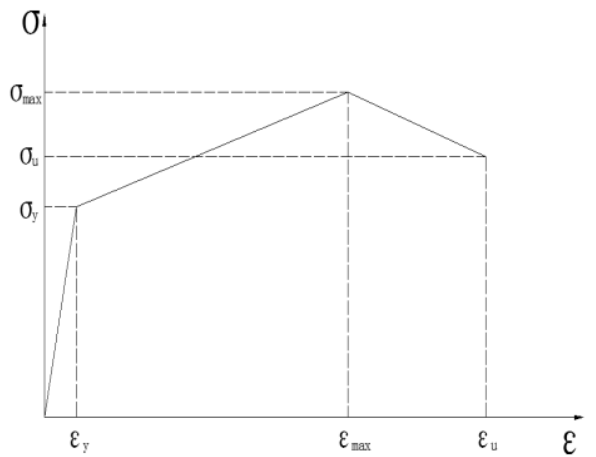

Fig. 5 The Form of Constitutive of C-type steel Fig. 6 The Loading System of C-type Steel

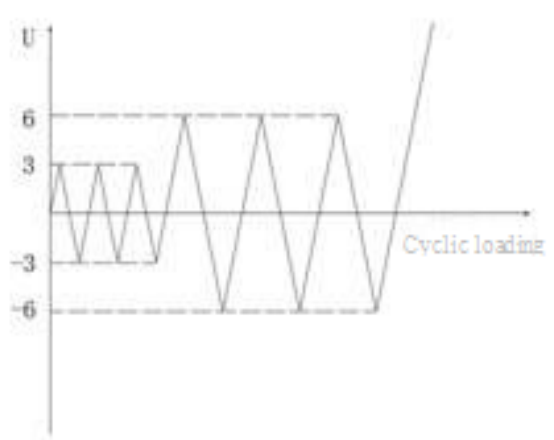

\section{Loading System}

Use the displacement cyclic loading system, each level of cyclic loading three times, shown in Figure 6.

\section{Finite Element Parametric}

Select finite element software Ansys, cell type is shell181, the elastic modulus of the resulting drawn test, constitutive select multiple linear kinematic hardening model. Use uniform meshing, constraint six degrees of freedom of all the nodes in one end. Finite element model shown is in Figure 7.

\section{The Results Analysis}

Solving the finite element model, you can get damage morphology of the specimen, top load-displacement curve. Classical mechanics can judge the position of the member after the failure at the boundary member, after calculated, we get the von mises stress cloud, shown in Figure 8.

Figure 8 shows that: member of simultaneous bending failure is accompanied by torsional response. 


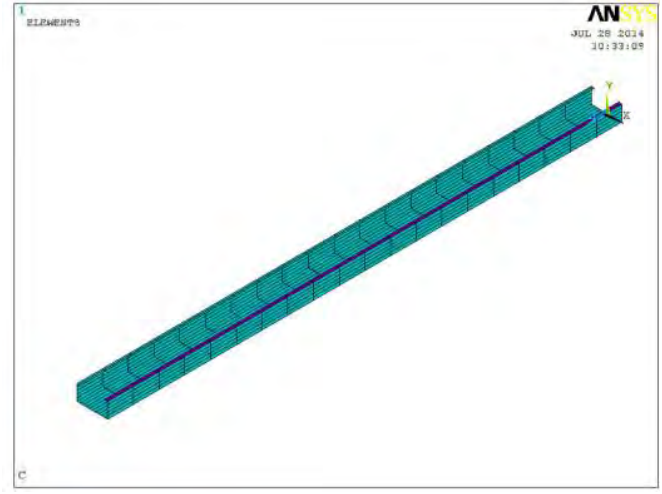

Fig. 7 Finite Element Model of C-type Steel

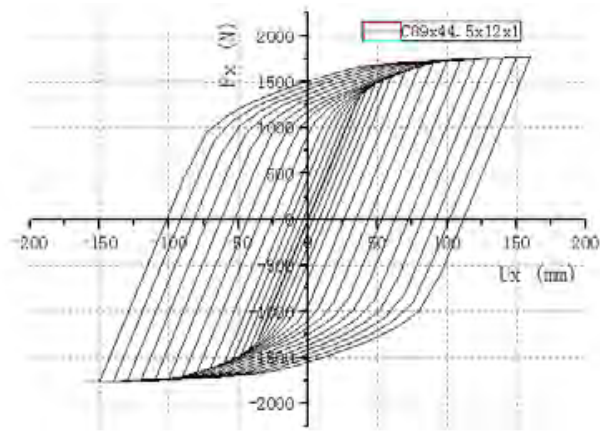

C89

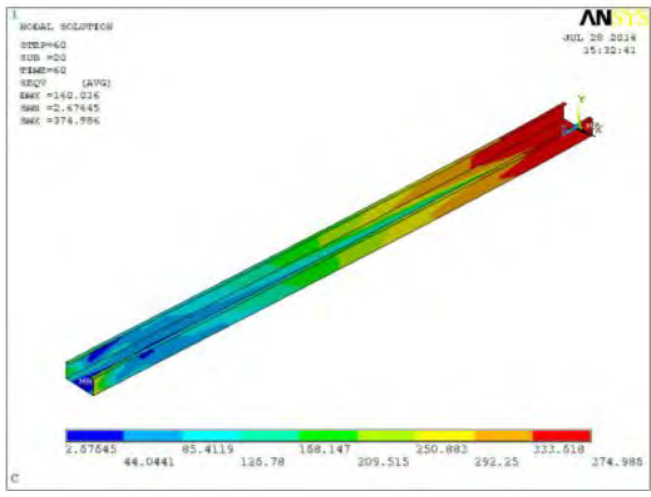

Fig. 8 Failure Stress Cloud

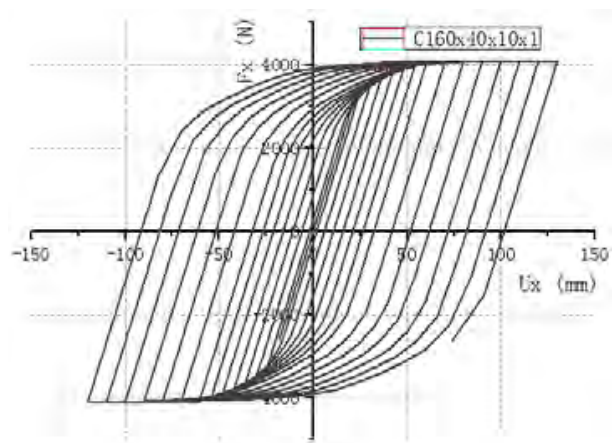

C160

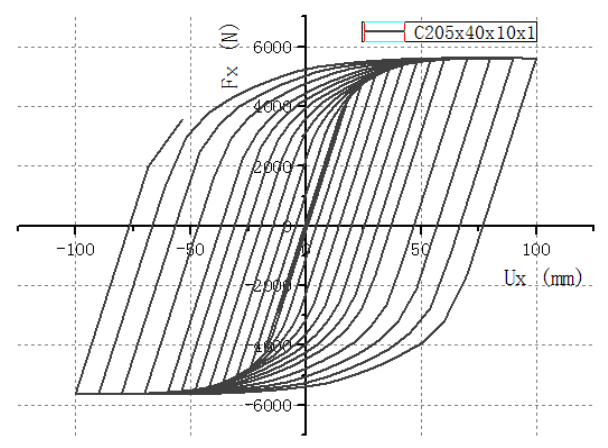

$\mathrm{C} 205$

Fig. 9 Load-displacement Curve of Member

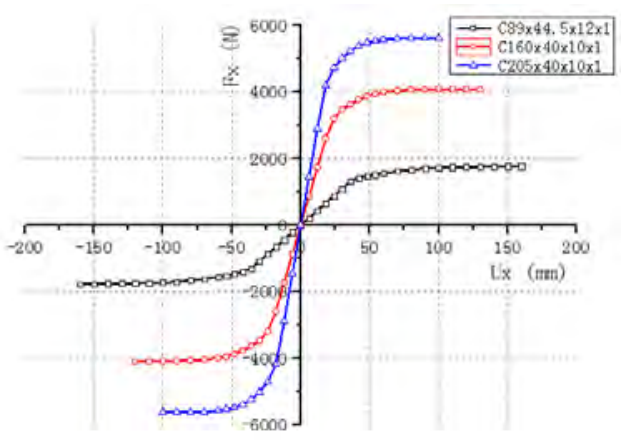

Fig. 10 Skeleton Curve

In figure 9 and figure 10, hysteresis curve of each specimen changes with the load has following the law: in Initial loading, the specimen in the elastic phase, hysteresis curve is substantially linear, stiffness remain constant; With the ends of the displacement load increases, the specimens rapidly into the elastoplastic phase from the elastic phase, hysteresis loop area increases, unloaded to zero 
residual deformation occurs, stiffness gradual degradation. The necking phase of material constitutive model did not happen, because the material ultimate strain of 0.24 , the component into the destruction phase requires a large displacement load, and the displacement load is too large so that the occurrence of bending torsion coupling destruction of member, so members did not experience the decline in segment. The cross-sectional dimensions of member have a greater impact on capacity, $\mathrm{C} 89 \times 44.5 \times 12 \times 1$ ultimate bearing capacity of approximately $1.80 \mathrm{kN}, \mathrm{C} 160 \times 40 \times 10 \times 1$ ultimate bearing capacity of approximately $4.10 \mathrm{kN}, \mathrm{C} 205 \times 40 \times 10 \times 1$ ultimate bearing capacity of approximately $5.61 \mathrm{kN}$.

Ductility refers the deformation capacity of structure or component from the yield began to reach the maximum carrying capacity or carrying capacity no significant drop in subsequent periods, ductility size usually expressed by ductility factor. Ductility factor is defined as the ratio of damage displacement and yield displacement of the structure or component.

Three group members have good ductility, indirectly reflects C-type cold-formed thin-walled steel members with good seismic performance.

Tab. 3 the Sectional Dimensions of C-type Steel

\begin{tabular}{|c|c|}
\hline Type & Ductility factor \\
\hline C89 & 5.33 \\
\hline C160 & 7.22 \\
\hline C205 & 5.56 \\
\hline
\end{tabular}

\section{Conclusion}

Conduct material test on cold-formed thin-walled steel, do hysteretic performance analysis of three groups of a single C-type cold-formed thin-walled components based on material physical parameters, obtain: coupling occur bending torsion coupling damage under cyclic loads; Sectional dimensions of members under cyclic loading has a greater impact on the carrying capacity; The batch cold-formed thin-walled steel material with good ductility.

\section{References}

[1]Xuhong Zhou, Yu Shi, Tianhua Zhou. Lower cold-formed thin-walled steel residential system[J]. Architecture and Civil Engineering, 2005, 22(2): 1-14.

[2]Nabil A Rahman. Cold-Formed Steel Stud-Plank System for Mid-Rise Construction[C]. St.Louis: Proceedings of the 2006 Structures Congress, Brad Cross, 2006.

[3]Miller T., Pekoz T.. Behavior of Gypsum-Sheathed Cold-Formed Steel Wall Studs [J]. Journal of Structural Engineering, ASCE, 1994, 120(5):1644-1650.

[4]Zuyan Shen, Yuanqi Li, Lei Wang, Yanming Wang, Hongwei Xu. The yield strength 550MPa high-strength cold-formed steel members Axial Compression Reliability Analysis[J]. Journal of Building Structures, 2006, 27(03): 26-33.

[5]The People's Republic of China Ministry of Construction. GB50018-2002 cold-formed thin-walled steel Technical Specifications[S]. Beijing: China Planning Press, 2002.

[6]Yu Shi, Xuhong Zhou, Xiaoli Yuan, Shaofeng Nie. Cold - formed channel axial compressive strength component capacity reduction method[J]. Journal of Building Structures, 2010, 31(9): $78-86$.

[7]General Administration of Quality Supervision Inspection and Quarantine of People's Republic of China, Standardization Administration of China. GB / T 228.1-2010 stretch metallic materials Test Part 1: Room temperature Test method[S]. Beijing: China Standard Press, 2010. 